\title{
Synthesis and Characterization of Functionalized Polystyrene Using ATRP with Strong Base Technique
}

\author{
E. Vakees ${ }^{1}$, J. Suresh $^{2}$, M. Kayalvizhi ${ }^{3}$, V. V. Srinivasan ${ }^{4}$ and A. Arun ${ }^{5}$ \\ ${ }^{1,2,3}$ P.G. and Research Department of Chemistry, Government Arts College, Tiruvannamalai-606603, \\ Tamilnadu, India \\ ${ }^{4}$ Department of Chemistry, Anna University, Chennai - 600 025, Tamilnadu, India
}

\begin{abstract}
This paper deals with a simple method for the synthesis of functionalised polystyrene using ATRP and strong base chemistry. The $\alpha, \Omega$ - dihydroxy terminated polystyrene $(\mathrm{OH}-\mathrm{PSt}-\mathrm{OH})$ and $\alpha, \Omega$ - diamine terminated polystyrene $\left(\mathrm{NH}_{2}\right.$-PSt- $\left.\mathrm{NH}_{2}\right)$ were prepared by reacting $\alpha, \Omega$ - Dibromo terminated polystyrene $(\mathrm{Br}$ $P S t-B r)$ with Potassiumhydroxide and Sodamide respectively. The synthesized polymers are characterized by different techniques. The Infrared (IR) spectrum confirms the formation of $-\mathrm{OH}$ and $-\mathrm{NH}_{2}$ as end group. The weight average molecular weight $(M w)$ of the synthesized polymer is determined by ${ }^{I} H N M R$ end group analysis, gel permeation chromatography (GPC) and mass spectrometric technique and found to be around $2000 \mathrm{~g} / \mathrm{mol}$. Thermogravimetric analysis (TGA) showed single stage decomposition cantered at $400^{\circ} \mathrm{C}$. The $\mathrm{Tg}$ value of the polymers is determined using Differential Scanning Colorimetric (DSC) method and found to be in the range from 58 to $60^{\circ}$.
\end{abstract}

Keywords: ATRP, amorphous, Industrial applications, strong base, polystyrene, solvent resistivity.

\section{Introduction}

In the past decade, the development of controlled/living radical polymerizations (CRP) [1,2] allows the synthesis of co-polymers not only with a predetermined degree of polymerization with narrow molecular weight distribution, but also with a high degree of functionality with desired microstructure. In the literature, several methods like Reversible addition fragmentation transfer polymerization (RAFT) [3,4] nitroxide - mediated polymerization (NMP) [5] bulk atom transfer radical polymerization [6] and atom transfer radical polymerization (ATRP) techniques were available for the synthesis of low molecular weight polymer. Among these techniques [7] ATRP is considered as a convenient method for the synthesis of low molecular weight polymer with a controlled degree of polymerization (DPs) [8] preserved functionality, microstructure / architectures etc.,. ATRP is considered by many researchers as one of the most effective free radical living polymerization methods due to the fact that, it can polymerize a wide variety of prepolymer / monomer [10-12].

The polymers produced by ATRP preserve the terminal halogen atom(s) and can be successfully converted into various end groups through appropriate transformation, especially nucleophilic substitutions [13]. The synthesised compound which contains bromine as a terminal group was used for a variety of chemical transformations to produce numerous types of end functional moieties, such as amino [14,15] hydroxyl [15] carboxy [16] groups, etc., [17-19]. Bifunctional polystyrene plays an important role in the synthesis of a variety of high performance polymers which are of commercial importance. Often these synthetic methods encounter difficulties in functionalising the polystyrene with narrow and desired molecular weights which leads to poor mechanical and elastic properties to the system. Moreover, commercially available bifunctionalised polystyrenes were found to be very expensive and practically not feasible to use for the commercial applications. Several reports available worldwide for the synthesis of functionalised polystyrene with narrow molecular weight distribution, but, none of them were found to be neither inexpensive nor simple synthetic route.

Herein, we are reporting a simple method for the synthesis of a functionalised polystyrenes, $\alpha, \Omega$ dihydroxy/diamino via two step method starting from synthesis of $\alpha, \Omega$-dibromo terminated polystyrene (PSt) by the ATRP technique followed by substitutions using strong bases like Potassium hydroxide and Sodamide respectively. The polymers were characterised by NMR, GPC, TGA, DSC and FT-IR techniques.

\subsection{Materials}

\section{Experimental Section}

Styrene (St, 99\%) was purchased from Aldrich chemicals (USA). After it was passed through a basic alumina column to remove the inhibitor, the styrene was stored under a nitrogen atmosphere at $0^{\circ} \mathrm{C}$. Potassium hydroxide, Copper bromide, and Dimethyl-2,6- Dibromoheptadioate (DM-2,6-DBHD) were purchased from Aldrich chemical Co, USA. N,N,N,N,N Pentamethyl diethyl triamine (PMDETA) is purchased from Aldrich, USA. Tetrahydrofuran, Toluene, Methanol, Dimethyl formamide, Neutral aluminium oxide and all other solvents were purchased from S.D Fine chemicals (INDIA) and used as such without further purification. 


\subsection{Characterization}

\subsubsection{Spectral measurements}

Alpha Bruker FT-IR spectrometer (Germany) was used for recording FT-IR spectrum and the spectra were recorded using the $\mathrm{KBr}$ pellet method. ${ }^{1} \mathrm{H}$ NMR spectra of the polymers were recorded on a Bruker spectrophotometer (Germany) operating at $320 \mathrm{MHz}$ at room temperature using deuterated chloroform $\left(\mathrm{CDCl}_{3}\right)$ as a solvent and tetramethylsilane (TMS) as an internal reference.

\subsubsection{Thermal analysis}

Thermogravimetric analysis (TGA) of the polymers was carried out with a Dupont 951 thermogravimertic analyser (Japan). About 8-10 mg of the sample was heated from 30 to $600^{\circ} \mathrm{C}$ at the heating rate of $10^{\circ} \mathrm{C} / \mathrm{min}$ in a nitrogen atmosphere with a gas flow rate of $100 \mathrm{ml} / \mathrm{min}$. DSC spectra were recorded on a Perkin Elmer DSC 7(Japan) apparatus equipped with a PE 7770 computer and TAS-7 software. 10-15mg of dried polystyrene sample was heated at a rate of $20^{\circ} \mathrm{C} / \mathrm{min}$ for recording DSC spectra.

\subsubsection{Molecular weight determinations}

The number average and weight average molecular weight of the polymer was obtained with a Shimadzu instrument(Japan) using THF as an eluent at a flow rate of $0.3 \mathrm{~mL} / \mathrm{min}$. A styragel column of pore size 103-106 $\AA$ was used. GC-MS spectrum of the polystyrene sample was analyzed using Shimadzu instrument.

\subsection{Solvent Resistivity}

Injection moulded sample of dimension $10 \times 10 \times 2 \mathrm{~mm}$ were used for solvent resistance measurements. Previously weighed samples were dipped in $50 \mathrm{ml}$ organic solvents and shaken for 60 minutes. After that, the solvent was decanted and the flask is dried for $24 \mathrm{~h}$ at $70{ }^{\circ} \mathrm{C}$. The dried flask was weighed again and from the weight loss, the amount of polymer sample dissolved in that solvent was calculated using Equ.(1).
Solvent Resistivity $=\frac{\mathrm{m}-\mathrm{m}_{0}}{\mathrm{~m}_{0}} \times 100 \%$
Equ.--------1

Where, $\mathrm{m}_{\mathrm{o}}$ and $\mathrm{m}$ is the weight of the substance $(\mathrm{mg})$ before solvent treatment and after solvent treatment respectively.

\subsection{Synthesis of $\square$, $\square$ - Dibromo terminated polystyrene (Br-PSt-Br)}

A Mixture of styrene $(90 \mathrm{ml}, 0.78 \mathrm{~mol})$ and toluene $(60 \mathrm{ml})$ was degassed in a Schlenk flask by 5 freezepump-thaw cycles. The ATRP catalyst, $\mathrm{CuBr}(0.75 \mathrm{~g}, 5.1 \mathrm{mmol})$ and PMDETA $(1.2 \mathrm{ml}, 4.2 \mathrm{mmol})$ was added to the above mixture. $2.25 \mathrm{ml}(4.5 \mathrm{mmol})$ of the difunctional initiator, dimethyl- 2,6- dibromoheptanedioate (DM 2,6-DBHD) was added last, and the reaction was stirred at $80^{\circ} \mathrm{C}$ degree for $140 \mathrm{~min}$. When the monomer conversion reached $30 \%$, the reaction mixture was diluted with THF, and the solution was passed through a column containing neutral alumina to remove the catalyst. The absorbent in the column washed with THF (30$40 \mathrm{ml}$ ) and the resulting solution polymer was concentrated by rotary evaporation.

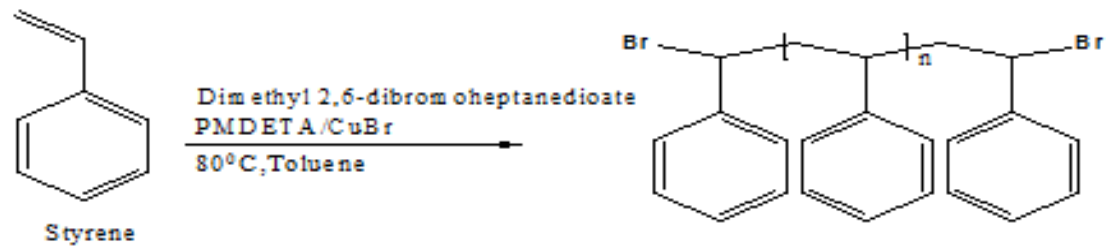

$\alpha, \Omega$, Dibromo terminated polystyrene

\section{Scheme 1: Synthesis of $\alpha, \Omega$-dibromo terminated polystyrene.}

The polymer was precipitated in cold methanol and dried under vacuum, the yield was $28 \mathrm{~g}(30 \%) .{ }^{1} \mathrm{H}$ $\operatorname{NMR}(\delta, \mathrm{ppm})$ : 7.1-7.3 (m, 5H, aromatic proton), $4.7(\mathrm{t}, 1 \mathrm{H},>\mathrm{C} \underline{\mathrm{H}}-\mathrm{Br}), 2.7(\mathrm{~m}, 1 \mathrm{H},-\mathrm{C} \underline{\mathrm{H}}-), 2.2\left(\mathrm{t}, 2 \mathrm{H},-\mathrm{C}_{2}-\right)$. FTIR $\left(\mathrm{cm}^{-1}\right)$ : 3024 (aromatic C-H), 2848 (aliphatic $\left.\mathrm{C}-\mathrm{H}\right), 1594$ (aromatic $\mathrm{C}=\mathrm{C}$ ), 1493 and $1450\left(\mathrm{CH}_{2}\right.$ bending frequency), $1335 \mathrm{~cm}^{-1}$ and $965\left(\mathrm{Ar}-\mathrm{CH}_{2}-\mathrm{Br}\right)$.

\subsection{Synthesis of $\square$, $\square$-dihydroxy terminated polystyrene (OH-PSt-OH)}

$10 \mathrm{~g}(0.0052 \mathrm{~mol})$ of Br-PSt-Br was dissolved in $250 \mathrm{ml}$ of DMF in Schlenk flask and was degassed by freeze-pump-thaw cycles. With this solution $6 \mathrm{~g}(0.28 \mathrm{~mol})$ of Potassium hydroxide dissolved in $15 \mathrm{ml}$ methanol was added drop by drop with constant stirring at $80^{\circ} \mathrm{C}$ under nitrogen atmospheric condition. The content of the 
flask is stirred for $8 \mathrm{hrs}$ at $80^{\circ} \mathrm{C}$. Finally the $\mathrm{OH}-\mathrm{PSt}-\mathrm{OH}$ was precipitated by adding the reaction mixture to an excess of methanol with rapid stirring. The product is filtered through ordinary filter paper and dried in air.<smiles>BrC1CC2CC3c4ccccc4C2(c2ccccc23)C(Br)C1Br</smiles>

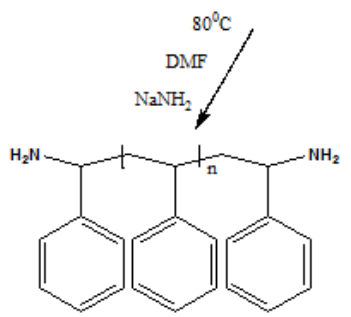

$\alpha, \Omega$, Diamino terminated polystyrene $\left(\mathrm{NH}_{2}-\mathrm{PSt}-\mathrm{NH}_{2}\right)$

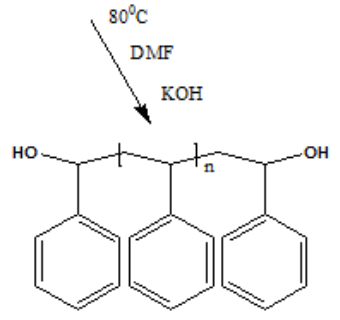

$\alpha, \Omega$, Dihydroxy terminated polystyrene $(\mathrm{OH}-\mathrm{PSt}-\mathrm{OH})$

Scheme 2: Synthesis of $\alpha, \Omega$-dihydroxy and $\alpha, \Omega$-diamino terminated polystyrene.

Yield: $8.9 \mathrm{~g}(89 \%) .{ }^{1} \mathrm{H}$ NMR $(\delta, \mathrm{ppm}): 7.1-7.3(\mathrm{~m}, 5 \mathrm{H}$, aromatic proton), $4.4(\mathrm{t}, 1 \mathrm{H},>\mathrm{C} \underline{\mathrm{H}}-\mathrm{OH}), 2.8(\mathrm{~m}, 1 \mathrm{H},-$ Cㅂ-), 2.1 (t, 2H, - $\underline{\mathrm{C}}_{2}$ ). FT-IR ( $\left.\mathrm{cm}^{-1}\right): 3343(-\mathrm{OH}), 3024$ (aromatic C-H), 2920, 2848 (aliphatic C-H), 1594 (aromatic $\mathrm{C}=\mathrm{C}), 1491,1440$ ( $-\mathrm{CH}_{2}$ bending), $1161(>\mathrm{C}-\mathrm{O})$ and $1054(>\mathrm{CH}-\mathrm{OH})$.

\subsection{Synthesis of $\square$, $\square$-diamine terminated polystyrene $\left(\mathrm{NH}_{2}-\mathrm{PSt}-\mathrm{NH}_{2}\right)$}

$5 \mathrm{~g}(0.0026 \mathrm{~mol})$ of Br-PSt-Br was dissolved in $100 \mathrm{ml}$ of DMF in Schlenk flask and was degassed by freeze-pump-thaw cycles. With this solution $3 \mathrm{~g}(0.14 \mathrm{~mol})$ of Sodamide dissolved in $15 \mathrm{ml}$ of methanol were added drop by drop with constant stirring at $70^{\circ} \mathrm{C}$ under nitrogen atmospheric condition. The content of the flask was stirred for $8 \mathrm{hrs}$ at $70^{\circ} \mathrm{C}$. Finally the $\mathrm{H}_{2} \mathrm{~N}-\mathrm{PSt}-\mathrm{NH}_{2}$ was precipitated by adding the reaction mixture to an excess of methanol with rapid stirring. The product was filtered through ordinary filter paper and dried in air. Yield: 4.3g (90\%). ${ }^{1} \mathrm{H}$ NMR $(\delta, \mathrm{ppm})$ : 6.9-7.2 (m, 5H aromatic), $4.0\left(\mathrm{~m}, 1 \mathrm{H},>\mathrm{CH}-\mathrm{NH}_{2}\right), 2.8(\mathrm{~m}, 1 \mathrm{H},-\mathrm{CH}-)$, $2.1\left(\mathrm{~m}, 4 \mathrm{H},-\mathrm{CH}_{2}-\right.$ and $\left.\mathrm{NH}_{2}\right)$. FT-IR $\left(\mathrm{cm}^{-1}\right): 3389\left(>\mathrm{CH}-\mathrm{NH}_{2}\right), 3000,3024$ (aromatic $\left.\mathrm{C}-\mathrm{H}\right), 2920,2848$ (aliphatic $\mathrm{C}-\mathrm{H}), 1563\left(-\mathrm{C}-\mathrm{NH}_{2}\right), 1594$ (aromatic $\left.\mathrm{C}=\mathrm{C}\right), 1499,1458,\left(\mathrm{CH}_{2}\right.$ bending frequency) and $903(\mathrm{C}-\mathrm{N}$ terminal).

\section{Results And Discussion}

Functionalised and narrow molecular weight polystyrene was prepared using the combined technique of ATRP and strong base. The dibromo derivative of low molecular weight polystyrene is synthesized using the ATRP technique presented elsewhere (Scheme 1) (Hasneen et al., 2007 and Tsarevsky et al., 2005). The dibromo polystyrene is effectively converted into the hydroxyl and amine functionalisation using strong bases like Potassium hydroxide and Sodamide respectively (Scheme 2). The synthesized polymers were characterized by FT-IR, NMR, GPC, GC-MS and TGA/DTA techniques.

\subsection{FT-IR}

FT-IR spectrum of the functionalised polymers is shown in the Fig.1. Important FT-IR peaks of the polymer are depicted in the Table 1. FT-IR result of the synthesized Br-PSt-Br confirms the appearance of Ar$\mathrm{CH}_{2}-\mathrm{Br}$ at $965 \mathrm{~cm}^{-1}$ and $1335 \mathrm{~cm}^{-1}$. 


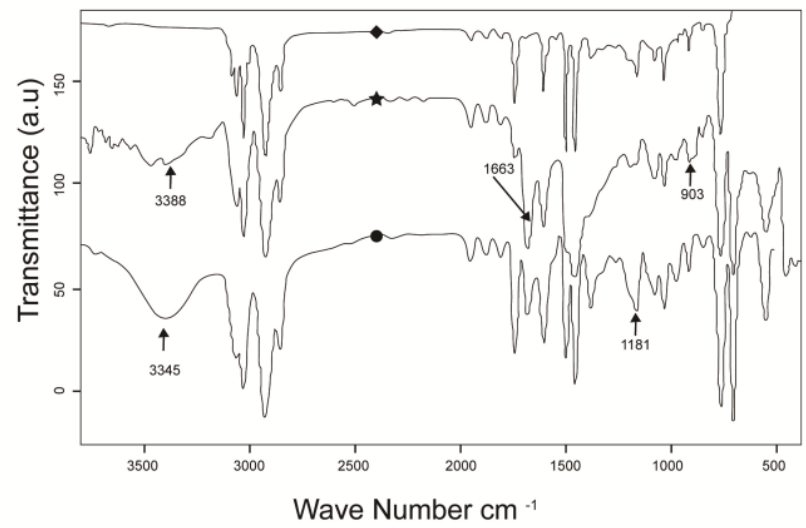

Figure 1: Comparative of the FT-IR spectrum of Br-PSt-Br $(\bullet) \mathrm{NH}_{2}-\mathrm{PSt}-\mathrm{NH}_{2}$ ( 3 \%H-PSt-OH (

In an OH-PSt-OH spectrum, the appearance of a peak at 3345 confirms the presence of hydroxyl group and at the same time the disappearance peak at 1335 confirms the absence of the bromide group at the terminal position of the polystyrene. Similarly, the amine functionalised polystyrene shows an intense peak at $3389 \mathrm{~cm}^{-1}$ for $\mathrm{NH}_{2}$ and the disappearance of peak at $1335 \mathrm{~cm}^{-1}$ indicates the complete conversion of bromine into amine group.

Table 1: Important FT-IR data of the synthesised polymers

\begin{tabular}{cccc}
\hline S.No. & Polymer code & FT-IR Frequency in $\mathrm{cm}^{-1}$ & Description \\
\hline 1 & $\mathrm{Br}-\mathrm{PSt}-\mathrm{Br}$ & 965 and 1335 & $>\mathrm{C}-\mathrm{Br}$ \\
2 & $\mathrm{OH}-\mathrm{PSt}-\mathrm{OH}$ & 3422 and 1161 & $-\mathrm{OH}, \mathrm{C}-\mathrm{O}$ \\
3 & $\mathrm{NH}_{2}-\mathrm{PSt}-\mathrm{NH}_{2}$ & 3388,1653 and 903 & $-\mathrm{NH}_{2},-\mathrm{C}-\mathrm{N}$ \\
\hline
\end{tabular}

\subsection{Study of Molecular Weight}

The molecular weight of the compound was determined by using NMR, GC-MS and GPC technique. All these techniques confirm that the weight average molecular weight $\left(\mathrm{M}_{\mathrm{w}}\right)$ of the synthesised polymers was around $2000 \mathrm{~g} / \mathrm{mol}$ and there were not much difference between the polymers $\mathrm{Br}-\mathrm{PSt}-\mathrm{Br}$, OH-PSt-OH and $\mathrm{NH}_{2}{ }^{-}$ PSt- $\mathrm{NH}_{2}$ which confirms that the basic polymer structure is preserved during the functionalisation process.

\subsection{1. ${ }^{1} \mathrm{H}$ NMR}

${ }^{1} \mathrm{H}$ NMR is a convenient technique to calculate the molecular weight of the low molecular weight polymer by end group analysis method. For the polymer OH-PSt-OH, the peaks at 7.1-7.3ppm (Aromatic, 5 proton) and $4.4 \mathrm{ppm}$ (1 protons, $\mathrm{CH}$ attached to $\mathrm{OH}$ group) represented the number of styrene molecule and the end group present in the polymer chain respectively. Since the two peaks were well distinct from each other, the integral values of these two peaks could be conveniently taken for determining the composition of the copolymer. The following equation was used for the calculation of molecular weight for the copolymer OH-Pst$\mathrm{OH}$.

$$
\begin{gathered}
C=\frac{\text { integaral value of aromatic proton }(\mathrm{Ia})(7.1-7.3 \mathrm{ppm})}{\text { Integral value of }-\mathrm{CH}-\mathrm{OH} \text { proton }(\mathrm{Im})(4.4 \mathrm{ppm})}--(2) \\
\text { Number of styrene units present in the polymer chain will be, } \\
\qquad m_{1}=\frac{C}{5} \text { and } \quad M w=\left[m_{1} \times 104\right]+34
\end{gathered}
$$

(Since each styrene molecule contains 5 aromatic protons)

Similarly, the molecular weight of the $\mathrm{Br}-\mathrm{PSt}-\mathrm{Br}$ and $\mathrm{NH}_{2}-\mathrm{PSt}-\mathrm{NH}_{2}$ were calculated and found to be around $2000 \mathrm{~g} / \mathrm{mol}$. The integral values of the aromatic $\left(\mathrm{I}_{\mathrm{a}}\right)$ and methine $\left(\mathrm{I}_{\mathrm{m}}\right)$ protons of the polymers are presented in the Table 2 .

Table 2: NMR Integral value used in the calculation for the molecular weight of the synthesised polymers

\begin{tabular}{ccccc}
\hline S.No. & Polymer code & $\mathrm{I}_{\mathrm{a}}$ & \multicolumn{2}{c}{$\mathrm{I}_{\mathrm{m}}$} \\
\hline 1 & $\mathrm{Br}-\mathrm{PSt}-\mathrm{Br}$ & 15 & 0.17 & $\mathrm{C}=\mathrm{I}_{\mathrm{a}} / \mathrm{I}_{\mathrm{m}}$ \\
2 & $\mathrm{OH}-\mathrm{PSt}-\mathrm{OH}$ & 14 & 0.17 & 88 \\
3 & $\mathrm{NH}_{2}-\mathrm{PSt}-\mathrm{NH}_{2}$ & 12 & 0.14 & 82 \\
\hline
\end{tabular}


The molecular weight of the synthesised polymers calculated through ${ }^{1} \mathrm{H}$ NMR is presented in the Table 3. The data confirm that the molecular weight of the synthesized polymers is found to be in the range of $2000 \mathrm{~g} / \mathrm{mol}$ which is the expected molecular weight. Also, it is concluded that, during the functionalisation process the polymer chain retained its stability confirmed by the unaltered molecular weight.

\subsubsection{GPC}

Similar to the NMR, the molecular weight of the polymer were determined by the GPC and presented in the Table 3. The GPC curve of the dihydroxy terminated polystyrene is presented in the Fig.2. The number and weight average molecular weight of the dihydroxy polystyrene were 1380 and 1551 respectively, with the polydispersity value of 1.12 .

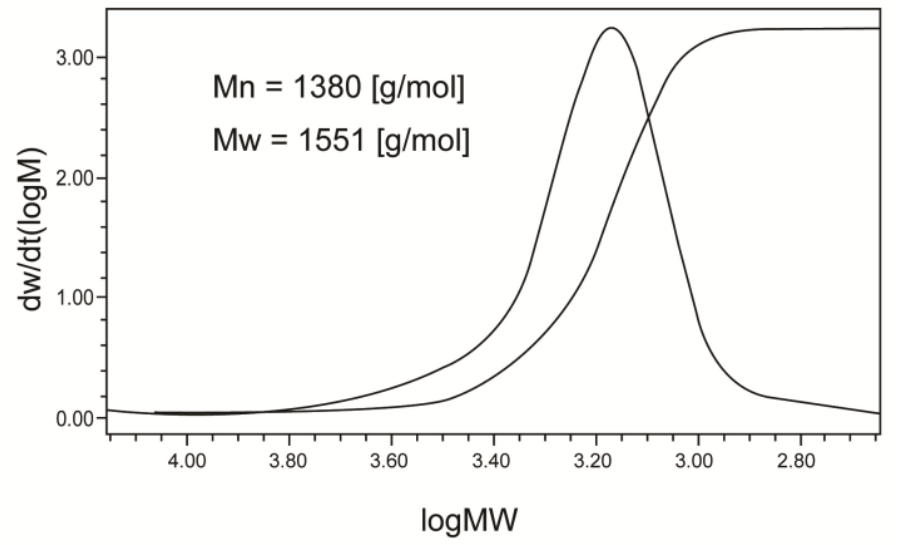

Figure 2: GPC curve of $\alpha, \Omega$-dihydroxy terminated polystyrene

The molecular weights of the synthesised polymers determined by the GPC were found to be comparable to each other. Also, it shows that the GPC values were concurrent with the NMR result and the low polydispersity (around 1.1) value is due to the ATRP method which employed in the polymerisation process.

\subsubsection{GC-MS}

GC-MS is the convenient technique to determine molecular weight of the low molecular weight polymer by fragmentation analysis method. The molecular ion peak value of the polymer was shown in the Table 3. GC-MS graph of the OH-PSt-OH is given in the Fig.3 as a representative of the polymer series.

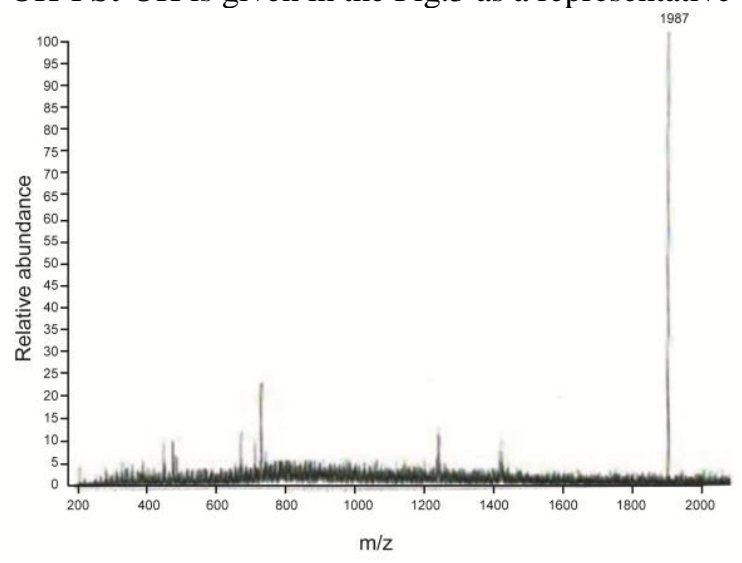

Figure 3: GC-MS spectrum of $\alpha, \Omega$-dihydroxy terminated polystyrene

Similar to NMR and GPC, the GC-MS value of the synthesised polymer showed a comparable molecular ion peak at 1999, 1987 and 1990 for Br-PSt-Br, OH-PSt-OH and $\mathrm{NH}_{2}-\mathrm{PSt}-\mathrm{NH}_{2}$ respectively.

Table 3: Molecular weight of the polymers determined by different technique

\begin{tabular}{ccccccc}
\hline & & \multicolumn{2}{c}{ NMR } & GC-MS & \multicolumn{2}{c}{ GPC } \\
\cline { 3 - 7 } S.No & Name of the Polymer & $(\mathrm{g} / \mathrm{mol})$ & {$\left[\mathrm{M}_{\mathrm{w}} \bullet^{+}\right]$} & $\begin{array}{c}\mathrm{M}_{\mathrm{w}} \\
{[\mathrm{g} / \mathrm{mol}]}\end{array}$ & $\begin{array}{c}\mathrm{M}_{\mathrm{n}} \\
{[\mathrm{g} / \mathrm{mol}]}\end{array}$ & $\mathrm{M}_{\mathrm{w}} / \mathrm{M}_{\mathrm{n}}$ \\
\hline 1 & Br-PSt-Br & 1942 & 1999 & 1800 & 1690 & 1.15 \\
2 & $\mathrm{OH}-\mathrm{PSt}-\mathrm{OH}$ & 1802 & 1987 & 1551 & 1380 & 1.12 \\
3 & $\mathrm{NH}_{2}-\mathrm{PSt}-\mathrm{NH}_{2}$ & 1800 & 1990 & 1560 & 1384 & 1.12 \\
\hline
\end{tabular}




\subsection{Thermal analysis}

\subsection{1. $\quad$ TGA}

Thermogravimetric analysis was used to estimate the percentage weight loss of the copolymer against temperature. The TGA and DTA curve of dihydroxy polystyrene is presented in Fig.4 as a representative of the functionalised polystyrene series.

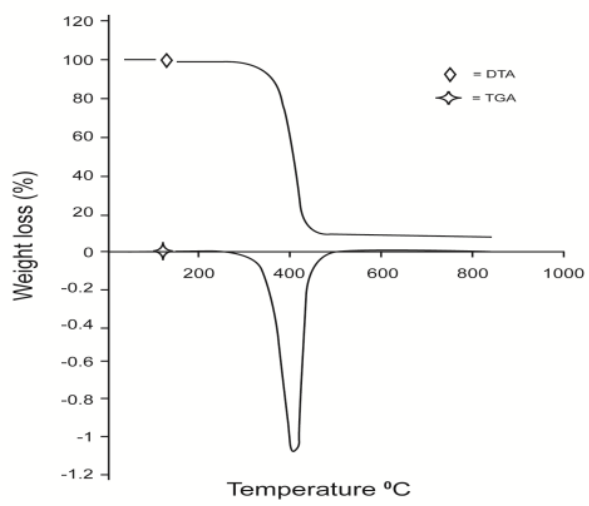

Figure 4: $\operatorname{TGA}(\diamond)$ and DTA ) curve of $\alpha, \Omega$-dihydroxy terminated polystyrene

Table 4 shows the initial and the final decomposition temperature of the functionalised polystyrene. These results confirm that the functionalised polystyrene shows a sharp single stage decomposition temperature centered on $400^{\circ} \mathrm{C}$ and consistent with the similar type polystyrene systems. The initial and final decomposition temperatures of the synthesised polystyrene are not varying much with one another confirming the high stability of the polymers during the functionalisation process.

\subsubsection{DSC}

The DSC data of the functionalised polystyrene are presented in Table 4, and the DSC curve of dihydroxy polystrene is presented in Fig. 5 as a representation of the polymer series. The $\mathrm{Tg}$ value of the functionalised polystyrene is centered around $58^{\circ} \mathrm{C}$ and does not vary very much with one another as consistent with the data reported for the similar molecular weight polystyrene.

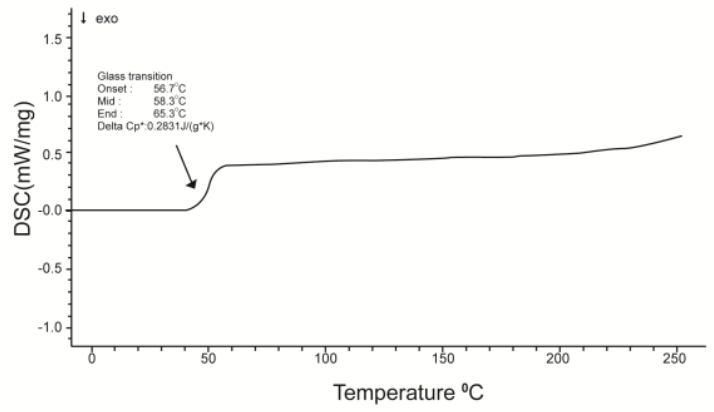

Figure 5: DSC curve of $\alpha, \Omega$-dihydroxy terminated polystyrene

But on a closer look, the Tg value of the polystyrene is in the order of dibromo $<$ dihydroxy $<$ diamine. This observed slight change in the $\mathrm{Tg}$ value may be due to the bulky end group present in the small polystyrene

Table 4: TGA and DSC data of the synthesized polymers

\begin{tabular}{cccccccc}
\hline \multirow{2}{*}{ S. No. } & \multirow{2}{*}{ Name of the polymer } & \multicolumn{3}{c}{ DSC $\left({ }^{\circ} \mathrm{C}\right)$} & \multicolumn{4}{c}{ TGA $\left({ }^{\circ} \mathrm{C}\right)$} \\
\cline { 3 - 8 } & & Tig & Tmg & Teg & D $_{\text {initial }}$ & D $_{\text {mid }}$ & D $_{\text {final }}$ \\
\hline 1 & Br-PSt-Br & 55.8 & 56.8 & 59.3 & 313 & 388 & 463 \\
2 & OH-PSt-OH & 56.7 & 58.3 & 60.5 & 315 & 400 & 464 \\
3 & $\mathrm{NH}_{2}-\mathrm{PSt}-\mathrm{NH}_{2}$ & 57.2 & 60.6 & 63.3 & 316 & 396 & 464 \\
\hline
\end{tabular}

Where, Tig = initial point, $\mathrm{Tmg}=$ midpoint, $\mathrm{Teg}=$ end point and $\mathrm{D}=$ Decomposition temperature chain. The effect of end group on the chain flexibility in functionalised polystyrene is clearly presented on the $\mathrm{Tg}$ value. This type of end group effect is often reported in several triblock copolymer systems [18,19]. 


\subsection{Solvent Resistivity}

Amorphous polymers like $\alpha, \Omega$-dibromo, $\alpha, \Omega$-dihydroxy and $\alpha, \Omega$-diamino terminated polystyrene were very easily attacked by the solvent on their physical network points thereby providing dimensional instability to the system. The solvent resistivity was studied by suspending injection moulded bars in organic solvents at room temperature for 1 hour [20]. After drying the sample, the weight loss was determined. The solubility pattern of the amorphous polymers is depicted in Table 5 and found that the amorphous polymer is completely soluble in all tested solvents and thereby showing poor solvent resistivity.

\section{Conclusion}

$\alpha, \Omega$-dihydroxy and $\alpha, \Omega$-diamine terminated polystyrene were prepared using $\alpha, \Omega$-dibromo prepolymer which ii turn was prepared using ATRP technique. The synthesized polymers were characterised by IR, NMR, GPC, GC-MS and TGA techniques. The IR results confirmed the formation of the functional group. The molecular weight of the polymers was calculated using NMR, GPC and GC-MS technique and found to be around $2000 \mathrm{~g} / \mathrm{ml}$ with narrow polydispersity value of 1.1 . The synthesised prepolymer are stable up to $400^{\circ} \mathrm{C}$ and showed single stage decomposition centered around $400^{\circ} \mathrm{C}$. The $\mathrm{Tg}$ of the polymer is found to be around $58^{\circ} \mathrm{C}$ and increasing with increasing the bulkiness of the end group. Synthesised prepolymer showed poor solvent resistivity in organic solvent. Therefore, these polymers can be used for further processing and application in different polymeric fields. Overall an effective and simple method for the synthesis of functionalized polystyrene is reported here and characterised with all available techniques.

\section{Acknowledgement}

We wish to thank the Department of Science and Technology (DST), India for their financial support for Dr. A. Arun under Fast Track Scheme for young scientists (No.SR/FT/CS-018/2009).

\section{References}

[1]. J. Lutz, T. Pakula and K. Matyjaszewski, Synthesis and properties of copolymers with tailored

[2]. sequence distribution by controlled/living; radical polymerization, ACS Symposium Series, 854, 2003,

268.

[3]. M. K. Georges, R. P. N. Veregin, P. M. Kazmaier and G. K. Hamer, narrow molecular weight resins by a free-radical polymerization process, Macromolecules, 26(11), 1993, 2987.

[4]. M. Kamigaito, T. Ando and M. Sawamoto, Matel catalyzed living radical polymerization, Chemical Revision, 101, $2001,3689$.

[5]. Holden G, Legge NR, Quirk R, Schroeder HE. Thermoplastic elastomers. (2nd Munich: Hanser Publishers, 1996).

[6]. M. Rodlert, E. Harth, I. Rees and C. J. Hawker, End-group fidelity in nitroxide-mediated living free-radical polymerizations, Journal of Polymer Science Part A : Polymer Chemistry 38, 2000, 4749.

[7]. D. Benoit, V. Chaplinski, R. Braslau and C. J. Hawker, Development of a universal alkoxyamine for living free radical polymerization, Journal of American Chemical Society 121, 1999, 3904.

[8]. T. E. Patten, J. Xia, T. Abernathy and K. Matyjaszewski, Polymers with very low polydispersities from atom transfer radical polymerization, Science 272, 1996, 866.

[9]. V. Coessens, T. Pintauer and K. Matyjaszewski, functional polymers by atom transfer radical polymerization, Progress in Polymer Sciences, 26, 2001, 337.

[10]. K. Matyjaszewski, T. E. Patten and J. Xia, Controlled/Living radical polymerization kinetics of the homogeneous atom transfer radical polymerization of Styrene, Journal of American Chemical Society, 119, 1997, 674.

[11]. J. Lutz, B. Kirci and K. Matyjaszewski, Synthesis of Well-defined alternating copolymers by controlled/"living" radical polymerization in the presence of lewis acids, Macromolecules 36 (9), 2003, 3136.

[12]. S. C. Hong, J. Lutz, Y. Inoue, C. Strissel, O. Nuyken and K. Matyjaszewski, Use of an immobilized/soluble hybrid ATRP catalyst system for the preparation of block copolymers, random copolymers and polymers with high chain end functionality, Macromolecules 36 (4), 2003,1075.

[13]. N.V. Tsarevsky, T.Sarbu Pakula and K. Matyjaszewski, Synthesis of styrene - acrylonitrile (SAN) copolymers and related block copolymers by atom transfer radical polymerization, Macromolecules, 35,2002, 6142.

[14]. J. F. Jean, N. Jahed and K. Matyjaszewski, Preparation and characterization of graft terpolymers with controlled molecular structure, Journal of Polymer Science Part A : Polymer Chemistry 42, 2004, 1939.

[15]. K. Kulangiappar, M. Anbu Kulandainathan and T. Raju, Conversion of benzylic bromides to benzaldehydes using sodium nitrate as an oxidant, Indian Engineering Chemistry Revision, 49, 2010, 6670.

[16]. I. lee and F. S. Bates, Synthesis, structure and properties of alternating and random poly(styrene-b-butadiene) multiblock copolymers, macromolecules 46 (11), 2013, 4529.

[17]. K. Matyjaszewski, Atom Transfer Free Radical Polymerization, Chapter for Encyclopedia of Materials: Science and Technology (Elsevier, Amsterdam, 2001, p 355-365)

[18]. N. V. Tsarevsky, B. S. Sumerlin and K. Matyjaszewski, Step growth "click" coupling of telechelic polymers prepared by atom transfer radical polymerization, Macromolecules 38 (9), 2005, 3558

[19]. A. Arun and R. J. Gaymans, Structure and properties of mono, di, tri and multiblock segmented copolymers with diamide hard segments, Macromolecular Chemistry and Physics 209 (8), 2008, 854

[20]. E. Bhoje Gowd, K. Tashiro and C. Ramesh, Structural correlation between crystal lattices and lamellar morphology in the phases transitions of uniaxially oriented syndiotactic polystyrene as revealed by simultaneous measurements of WAXS, Macromolecule 41(7), 2541-2554

[21]. R. Stephen, C. M. Gibon, M. Weber and R.J. Gaymans, Modifying an amorphous polymer to a past crystalling semi-crystalline material by copolymerization with monodisperses amide segments, Journal of polymer science part A: Polymer Chemistry 48 , 2010, 63 . 